\title{
ANALOGUE AERIAL-PHOTOPRAPHS EXTERNAL ORIENTATION RECONSTRUCTION BASED ON GEOPORTAL DATA
}

\author{
PIOTR DZIESZKO \\ Adam Mickiewicz University, Institute of Geoecology and Geoinformation, Poznań, Poland
}

Manuscript received: May 21, 2011

Revised version: September 6, 2011

DzIEszKo P.., 2011. Possibility of analogue air photo external orientation reconstruction based on geoportal data used for digital orthophotomap creation. Quaestiones Geographicae 30(3), Bogucki Wydawnictwo Naukowe, Poznań, pp. 13-18, 4 Figs., 2 Tabs. ISBN 978-83-62662-75-3. ISSN 0137-477X. DOI 10.2478/v10117-011-0023-z

AвSTRACT: For acquisition of source data for geoinformation analyses is necessary to do some field works. This way of data acquisition is time-consuming. In this case, photogrammetric and remote sensed methods can be more effective choice. Especially orthophotomap extracting is more effective process in creation of geodata. It is good foundation for further analysis and nice extension of existing geographical information systems. Despite fast growth of photogrammetry there are plenty of analogue, archival airphotos which can be used for geoinformation analysis. They are quiet up to date and scanned in very high resolution which means they can be used for really reliable analysis. The problem is very important because many of analogue, archival air photos do not contain photogrammetric warp. The aim of this paper is expression of applicability of geoportal webpage, which is part of INSPIRE directive, that can be used for external orientation reconstruction when there is no other georeference data.

KEYWORDS: orthophotomap, photogrammetry, external orientation, geoportal, air-photos, analogue.

Piotr Dzieszko, Institute of Geoecology and Geoinformation, Adam Mickiewicz University, ul. Dzięgielowa 27, 61-680

Poznań, e-mail:dzieszko@amu.edu.pl

\section{Introduction}

Information about external orientation of aerial photographs is collected automatically using digital aerial cameras during their acquisition. With analogue cameras, there is no such a comfort. If photos do not contain photogrammetric warp it is necessary to collect reference data which is needed to reconstruct external orientation using ground control points (Konecny 2001). Knowledge about external orientation is necessary for determining location of camera during data ac- quisition (Kurczyński 2006). It means that it is indispensable to collect reference data to reconstruct external orientation of aerial photographs. In this case, using data from national geoportal to reconstruct external orientation can be very significant. The main task of photogrammetry is to deliver information about topographical objects without physical contact with them (Konecny 2001). So if the photogrammetric method has to be supplemented by field works, its competitiveness is getting lower. 


\section{Study area and input data}

Three sets of images were used for creating orthophotomaps using reference data from geoportal. Images were taken on 20 may 2007. Aerial raid was made above Lubon, a town placed in Great Poland in the south of Poznań.

Three separate projects were created. Every project contained 2 strips of 4 images. For every project separate orthophotomap was created. The spatial resolutions of scanned images in projects were: $0.544 \mathrm{~m}, 0.272 \mathrm{~m}$ and $0.136 \mathrm{~m}$. A project with scanned images with $0.544 \mathrm{~m}$ resolution will be further called project $25 \%$. A project with scanned images with $0.272 \mathrm{~m}$ resolution will be further called project $50 \%$. And a project with scanned images with $0.136 \mathrm{~m}$ resolution will be further called a project $100 \%$. This terminology is used because original scanned images have resolution $0.136 \mathrm{~m} .0 .272 \mathrm{~m}$ means half of original resolution (50\%) and 0.544 means quarter of original resolution (25\%). Spatial resolution is the only feature which differences a projects. The spatial resolution of the images was decreased by author to determine the influence of spatial resolution on the quality of the orthophotomap when georeference data is obtained from geoportal. gov.pl webpage.

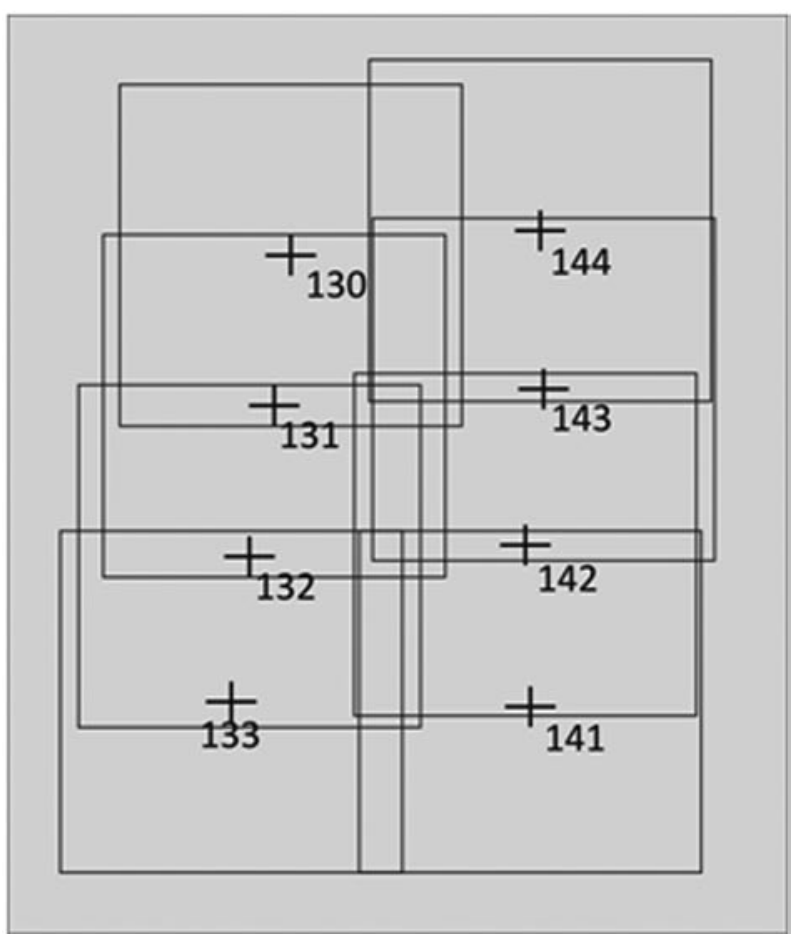

Fig. 1. Central points of air photos mutual location.
Original aerial photographs were taken by analogue aerial camera made by company Zeiss comapny, model RMK A 15/23 with nominal focal length $153 \mathrm{~mm}$. Real focal length after camera calibration was $152.504 \mathrm{~mm}$ (Zeiss Company 2007). Such a focal length value allows to collect aerial photographs in 1:10 000 scale from height of $1524 \mathrm{~m}$ and aerial photographs in 1:20 000 scale from height of $3048 \mathrm{~m}$. After scanning aerial photographs spatial resolution equaled $0.136 \mathrm{~m}$. Graphical software ${ }^{1}$ was used for leading photos to lower resolutions. The forward overlap for photos equaled $70 \%$. Side overlap was $50 \%$. On the figure 1 there are shown central points of each photos in projects.

\section{The collecting of ground control and tie points}

The reconstruction of exterior orientation is necessary to collect information about aerial camera location during data acquisition. It is essential step for further analysis - digital elevation model creating. Orthorectification process runs on the basis of digital elevation model. It is possible to extract orthophotomap using any digital elevation model of the study area. But it is also possible to extract digital elevation model using aerial photographs and on the basis of this model run orthorectification of the images. So in this case, digital elevation model creating is an intermediate step in the process of orthophotomap creating.

For ground control points it is essential to know $X$ and $Y$ location or geographical coordinates in used reference system and local height (Kurczyński 2006). PUWG 92 is reference system used in projects. Information about location and height of ground control points was collected from geoportal.gov.pl webpage which is designed in accordance with INSPIRE directive. Two geoportal's thematic layers were used during reconstruction of exterior orientation. Raster topographic map layer in 1:10 000 scale and layer with orthophotomap.

As regards ground control points (GCP), they are points that can be clearly identified on images

Adobe Photoshop CS3. 
and also their coordinates are known (Konecny 2001). It is possible to use various sources of data for collecting coordinates of GCPs. For example, other images which contain spatial reference, topographic maps, GPS waypoints and others. GCPs in projects are essential because they determine relationship between coordinates in raster system (columns and rows) and reference system coordinates ( $x, y$ and $z$ ). The quality of GCP has got direct influence on the quality of maths model.

Considering analogue aerial photographs, minimal number of GCPs is 3 to 4 for whole project. However it is recommended to use at least 3 GCPs for each image to provide appropriate level of accuracy (PCI Geomatics 2007).

As for methods, in every project the same GCPs were used. After collecting points for the project $100 \%$ they were exported to the text file and used in others projects. The assumption was to use at least 4 GCPs for image. Despite the fact that number of GCPs is 15 and number of images is 8 , the assumption was achieved because some GCPs were used for more than one image. It is highly recommended to use the same GCPs for as many images as it is possible. Then they have the same names, the same coordinates but different values of columns and rows (raster grid system). GCPs used for more than one image increase accuracy of math model because they link image objects with real position and also link objects located on different images.

First, on every image, the point was identified for make connection with its real position (Fig. 2). Next, the same point was found on geoportal orthophotomap thematic layer. From geoportal orthophotomap thematic layer, coordinates in PUWG 92 were collected. Raster and spatial coordinates were entered to the photogrammetric software form. The next step was to collect information about height of the point from 1:10 000 topographic raster map thematic layer on geoportal webpage.

Such a procedure was iterated for every image. It was essential to get at least 4 points for every image. In every project number of GCPs was 15 . But some of GCPs were used for 5 images.

The next necessary step for exterior orientation reconstruction is to collect tie points. Tie points are points which can be clearly identified
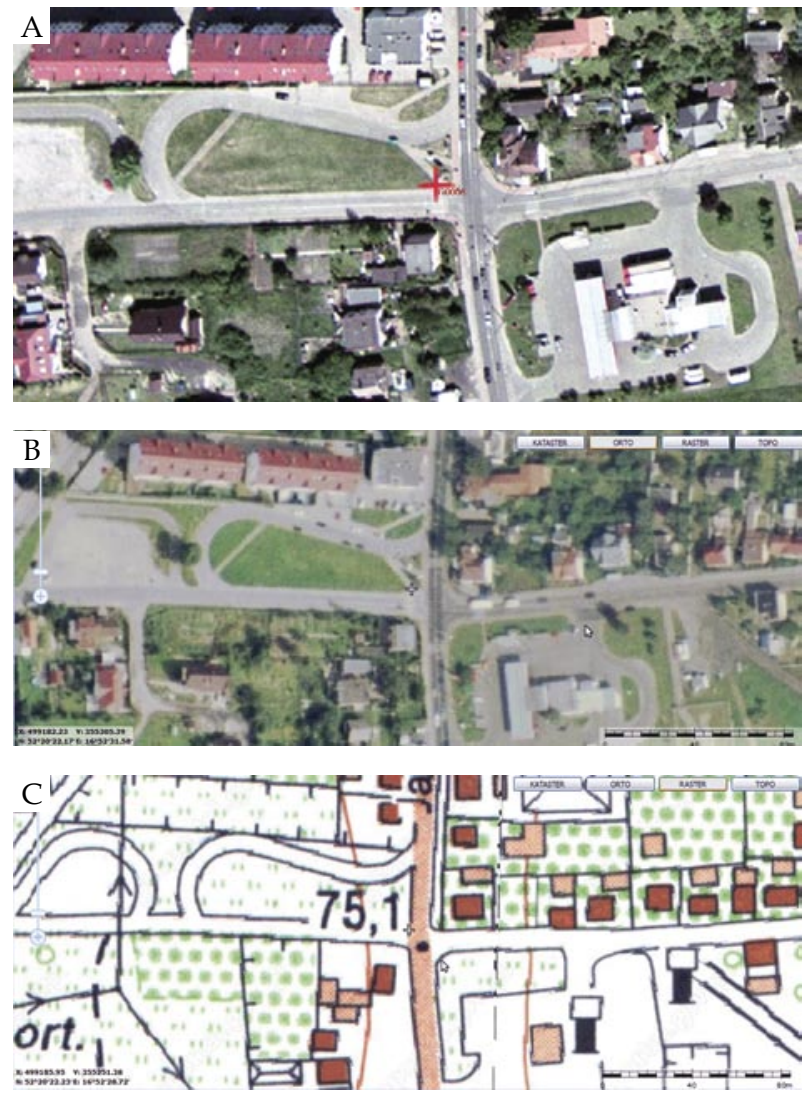

Fig. 2. Three windows used for collecting GCPs. A: one of the points indicated on used air-photo, B: the same point indicated in geoportal webpage (orthophotomap layer) C: the same point indicated in geoportal webpage (scanned topographic map layer).

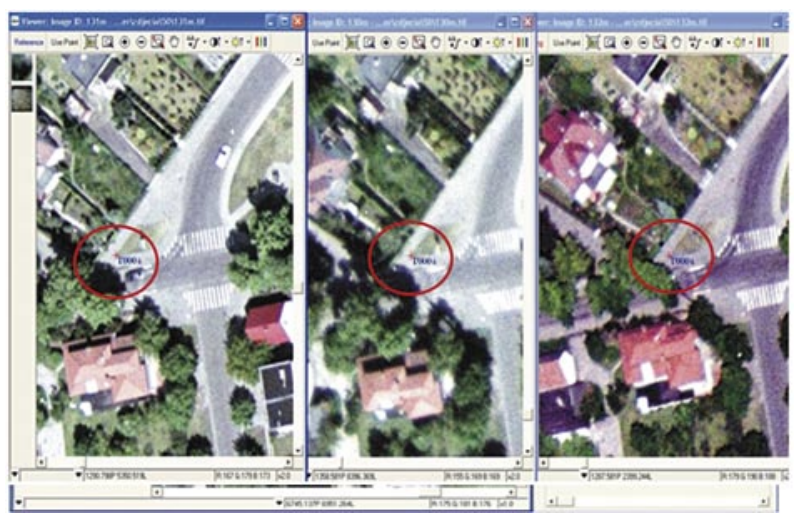

Fig. 3. T0004 tie point indicated on three different images.

in at least two images. They are used for linking content of images. First, it is essential to indicate point at one image and after that to find it on the other or others (it depends on overlap in project). It is not needed to know coordinates of tie points in used reference system but if this information 


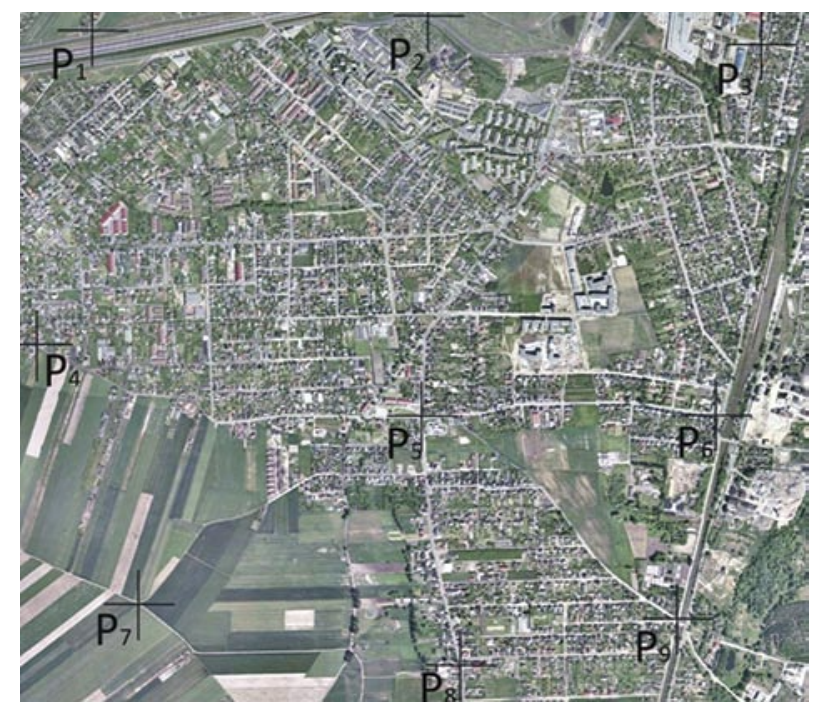

Fig. 4. The net of 9 points used for location error evaluation for final orthophotomaps.

is available, it is good to use them because they will be supplement for GCPs and they improve accuracy of the math model.

Collecting tie points means indicating point on first image and after that indicating it on every other image where it occurs (Fig. 3).

\section{Evaluation of orthophotomaps for different projects}

After reconstruction of exterior orientation, digital elevation model for every project was calculated. On its basis, orthorectification of input data was proceed and orthorectificated images were joined into one final orthophotomap. The quality of orthophotomap was evaluated based on the points location errors. In this way, it was possible to define how effective creating of orthophotomap from analogue aerial photographs can be, using geoportal webpage for reconstructing exterior orientation.

For the quality of orthophotomap evaluation in respect of point location precision, depending on the aerial photographs spatial resolution, the net of 9 points was inflicted on final orthophotomap. Next, for this 9 points coordinates in PUWG 92 reference system was collected from set of reference data (geoportal webpage) and from final maps in every project. The coordinate unit was, in this case, meters. In next step, difference between location of points on reference data and location on final maps was calculated.

Table 1. Coordinates of nine points choosed for verification of location errors Coordiantes in PUWG 92 (EPSG: 2180) reference system.

\begin{tabular}{|c|c|c|c|c|c|}
\hline Point name & Coordinates & Geoportal & Project 25\% & Project 50\% & Project 100\% \\
\hline \multirow{2}{*}{$\mathrm{P}_{1}$} & $\mathrm{X}$ & 354009.51 & 354009.56 & 354009.72 & 354009.75 \\
\cline { 2 - 6 } & $\mathrm{Y}$ & 500623.88 & 500623.51 & 500623.62 & 500623.49 \\
\hline \multirow{2}{*}{$\mathrm{P}_{2}$} & $\mathrm{X}$ & 355253.91 & 355253.98 & 355253.56 & 355252.36 \\
\cline { 2 - 6 } & $\mathrm{Y}$ & 500697.39 & 500697.34 & 500697.52 & 500698.10 \\
\cline { 2 - 6 } $\mathrm{P}_{3}$ & $\mathrm{X}$ & 356515.40 & 356515.12 & 356515.02 & 356513.28 \\
\hline \multirow{2}{*}{$\mathrm{P}_{4}$} & $\mathrm{Y}$ & 500594.08 & 500593.83 & 500593.23 & 500594.51 \\
\hline \multirow{2}{*}{$\mathrm{P}_{5}$} & $\mathrm{X}$ & 353758.39 & 353758.49 & 353758.12 & 353759.79 \\
\cline { 2 - 6 } & $\mathrm{X}$ & 499517.83 & 499517.58 & 499517.49 & 499517.18 \\
\hline \multirow{2}{*}{$\mathrm{P}_{6}$} & $\mathrm{Y}$ & 495226.65 & 355226.67 & 355227.19 & 355227.36 \\
\cline { 2 - 6 } & $\mathrm{X}$ & 356349.69 & 356348.68 & 356348.72 & 356348.29 \\
\hline \multirow{2}{*}{$\mathrm{P}_{7}$} & $\mathrm{X}$ & 359208.79 & 499208.50 & 499209.72 & 499211.46 \\
\hline \multirow{2}{*}{$\mathrm{P}_{8}$} & $\mathrm{Y}$ & 498502.34 & 498502.78 & 498503.05 & 498503.75 \\
\cline { 2 - 6 } & $\mathrm{X}$ & 355385.13 & 355385.80 & 355384.96 & 355386.55 \\
\hline \multirow{2}{*}{$\mathrm{P}_{9}$} & $\mathrm{X}$ & 498291.29 & 498291.24 & 498291.82 & 499292.16 \\
\cline { 2 - 6 } & $\mathrm{Y}$ & 4956181.64 & 356180.68 & 356180.36 & 356181.68 \\
\hline
\end{tabular}


This difference means location error of the point. For calculating average location error, for every difference in location, absolute value was calculated.

Table 2 shows errors of the point location on final orthophotomaps. The first conclusion from this comparison is that higher spatial resolution of input photos causes bigger errors on final maps. Calculating average error (meters) revealed that in project $50 \%$ it is two times higher than in project $25 \%$ and in project $100 \%$ it is two times higher than in project $100 \%$.

Additionally, it is possible to observe that fine results of the final orthophotomap were achieved only for projects $25 \%$ and $50 \%$. For the project $25 \%$ maximum noticed location error is smaller than raster grid extent of the final orthophotomap. And average error for this project is three times lower than raster grid extent of the final orthophotomap.

Considering project $50 \%$, average error is $3 \mathrm{~cm}$ higher than raster grid extent of the final orthophotomap. Maximum error is about three times higher than raster grid extent of the final orthophotomap. This results were considered as satisfactory with assumption that satisfactory result means that average error for the project is lower than two raster grid extent of the final orthophotomap.

This assumption was not achieved for the final orthophotmap from project $100 \%$. This orthophotomap has higher spatial resolution and higher errors than other projects. Average error for this projects equals $1.13 \mathrm{~m}$ so it means that average error is 4 times bigger than raster grid extent of the final orthophotomap. Maximum error in this project equals about $3.5 \mathrm{~m}$. It is about 12 times more than raster grid extent of the final orthophotomap. Therefore, for this project errors are very high and it cannot be considered as satisfied.

By that means, it is observed that with the increasing of spatial resolution of input scanned photos, the quality of orthophotomap calculated on the basis of geoportal reference data is decreasing. The increasing of spatial resolution of aerial photographs means that they are more precise and it is desirable activity. But in this case, due to using such a reference data with lower precision
Table 2. Subtraction of coordinates from reference data and final orthophotomaps in each project Error value (meters).

\begin{tabular}{|c|c|c|c|c|}
\hline Point name & $\begin{array}{c}\text { Coordi- } \\
\text { nates }\end{array}$ & $\begin{array}{c}\text { Project } \\
25 \%\end{array}$ & $\begin{array}{c}\text { Project } \\
50 \%\end{array}$ & $\begin{array}{c}\text { Project } \\
100 \%\end{array}$ \\
\hline \multirow{2}{*}{$\mathrm{P}_{1}$} & $x$ & 0.05 & 0.21 & 0.24 \\
\hline & $\mathrm{Y}$ & 0.37 & 0.26 & 0.39 \\
\hline \multirow{2}{*}{$\mathrm{P}_{2}$} & $x$ & 0.07 & 0.35 & 1.55 \\
\hline & $\mathrm{Y}$ & 0.05 & 0.13 & 0.71 \\
\hline \multirow{2}{*}{$\mathrm{P}_{3}$} & $x$ & 0.28 & 0.38 & 2.12 \\
\hline & $\mathrm{Y}$ & 0.25 & 0.85 & 0.43 \\
\hline \multirow{2}{*}{$\mathrm{P}_{4}$} & $x$ & 0.10 & 0.27 & 1.40 \\
\hline & $\mathrm{Y}$ & 0.25 & 0.34 & 0.75 \\
\hline \multirow{2}{*}{$\mathrm{P}_{5}$} & $x$ & 0.02 & 0.54 & 0.71 \\
\hline & $\mathrm{Y}$ & 0.19 & 0.26 & 0.19 \\
\hline \multirow{2}{*}{$\mathrm{P}_{6}$} & $x$ & 1.01 & 0.97 & 1.40 \\
\hline & $\mathrm{Y}$ & 0.29 & 0.93 & 2.67 \\
\hline \multirow{2}{*}{$\mathrm{P}_{7}$} & $x$ & 0.01 & 0.33 & 0.70 \\
\hline & $\mathrm{Y}$ & 0.44 & 0.71 & 1.41 \\
\hline \multirow{2}{*}{$\mathrm{P}_{8}$} & $x$ & 0.67 & 0.17 & 1.42 \\
\hline & $\mathrm{Y}$ & 0.05 & 0.53 & 0.87 \\
\hline \multirow{2}{*}{$\mathrm{P}_{9}$} & $x$ & 0.96 & 1.28 & 0.04 \\
\hline & $\mathrm{Y}$ & 0.23 & 1.69 & 3.42 \\
\hline Average eroor: & & 0.29 & 0.57 & 1.13 \\
\hline $\begin{array}{l}\text { Maximum error } \\
(\mathrm{m}):\end{array}$ & & 1.01 & 1.69 & 3.42 \\
\hline $\begin{array}{c}\text { Orthopho- } \\
\text { tomap spatial } \\
\text { resolution }(\mathrm{m}):\end{array}$ & & 1.1 & 0.54 & 0.27 \\
\hline
\end{tabular}

than input data, it does not affect so on the final effects.

With such a high spatial resolution, which was $0.136 \mathrm{~m}$ for project $100 \%$, precision of reference data is not appropriate. The highest spatial resolution available actually in geoportal's orthophotomap is about $0.5 \mathrm{~m}$ (Preuss \& Dygaszewicz 2006). It is about four times less than raster grid extent of input data in project $100 \%$ and about two times less than raster grid extent if input data in project $50 \%$. But precision of reference data is similar to precision of input data in project $25 \%$. For project $25 \%$ the quality of the final orthophotomap, considering point location errors, is the best. For others projects, more precise input data was used but with the same reference data, which lead to the deterioration of the final product. 


\section{Conclusions}

When using for creating orthophotomap analogue input data, availability of precise reference data is very essential. Without taking care of appropriate precision of reference data, it is impossible to achieve satisfactory results of the final orthophotomap quality, when orthophotomap is obtained from high resolution analogue aerial photographs. This means that in this case, increasing of spatial resolution of input scanned aerial photographs lead to deterioration of the final orthophotomap quality when using reference data available on geoportal webpage.

Nevertheless, for the orthophotomap calculated on the basis on aerial photographs with spatial resolution $0.544 \mathrm{~m}$, satisfactory results were obtained. It indicates that reference data from geoportal webpage can be effectively used for reconstructing of exterior orientation of analogue aerial photographs within some precision. For high resolution aerial photographs with raster grid extent smaller than half a meter reconstruction of exterior orientation is becoming difficult and quite impossible.

In addition, comfort of working with geoportal.gov.pl webpage is actually very low. Data is shared on the browser level, which means that work with this data is arduous and uncomfortable. So in this case, idea of the opening the GE-
OPORTAL 2 seems very prospective. GEOPORTAL 2 should increase the quality of working with the data for geospatial analysis.

What is also important, the spatial resolution of the available geoportal orthophotomap is not the same for whole country. Some parts of the country are covered by monochromatic and low resolution data. So it is impossible to reconstruct exterior orientation for whole country with the same quality of results.

Therefore, geoportal webpage can be used for reconstructing of exterior orientation but within some precision. So in some cases, if other data sources are unavailable, it is possible to lead photogrammetric analysis using geoportal reference data. But, if doing field measurements is available, it is recommended to do so. It will improve the quality of analysis.

\section{References}

Konecny G., 2001. Geoinformation, Remote Sensing, photogrammetry and geographic information systems. Taylor and Francis Foundation, London.

KuRCZYŃSKI Z., 2006. Lotnicze i satelitarne obrazowanie Ziemi. Oficyna Wydawnicza Politechniki Warszawskiej, Warszawa.

PCI Geomatics [Enterprises Inc.], 2007. Geomatica OrthoEngine 10.1 User Guide. Richmond Hill.

Preuss R., DygASZEWICZ J., 2006. Ortofotomapa w sieci - projekt Geoportal. Archiwum Fotogrametrii, Kartografii i Teledetekcji 16: 495-504. 